\title{
Influence of IGF1, TGF $\beta 1$, bFGF and G-CSF/M-CSF on the mRNA levels of selected matrix proteins, cytokines, metalloproteinase 3 and TIMP1 in rat synovial membrane cells
}

\author{
Anna Osiecka-Iwan, Stanislaw Moskalewski, Anna Hyc \\ Department of Histology and Embryology, Medical University of Warsaw, Warsaw, Poland
}

\begin{abstract}
Introduction. We have previously observed that rat synovial membranes incubated in medium containing cartilage interstitial fluid (CIF) responded by changes in the expression of hyaluronan synthases (HAS1 and HAS2), collagen type I, versican, aggrecan, lubricin, matrix metalloproteinases 2 and 3 (MMP2 and MMP3), tissue inhibitors of metalloproteinases (TIMP1, 2 and 3), transforming growth factor $\beta 1$ (TGF $\beta 1$ ), tumor necrosis factor (TNF), interleukin (IL) $1 \beta$ and IL-6. The aim of the study was to evaluate the influence of particular cytokines found in CIF on the gene expression of extracellular matrix (ECM) proteins in synovial membrane cells.

Material and methods. Synovial membranes (SMs) were removed from the knee joints of inbred, male Lewis rats and incubated with insulin-like growth factor 1 (IGF1), TGF $\beta 1$, basic fibroblast growth factor (bFGF) and granulocyte- macrophage colony-stimulating factors (G-CSF and M-CSF), either individually or in the combinations TGF $\beta 1 /$ IGF1, TGF $\beta 1 /$ IGF1/bFGF or G-CSF/M-CSF. Next, total RNA was isolated and the studied genes' expression was evaluated by real-time PCR.

Results. TGF $\beta 1 /$ IGF1 stimulated expression of HAS1, lubricin, collagen type I, aggrecan and TGF $\beta 1$, inhibited expression of MMP3 and TNF and had no effect on TIMP1 and IL-6 mRNA levels. TGF $\beta 1 /$ IGF1/bFGF stimulated the expression of HAS1, lubricin and TGF $\beta 1$ genes, inhibited the expression of TNF and had no effect of the expression of collagen 1, aggrecan, MMP3, TIMP1 and IL-6 genes. G-CSF/M-CSF stimulated the expression of aggrecan. TGF $\beta 1$, bFGF, and IGF1 applied individually exerted inhibitory effect on the expression of lubricin. TGF $\beta 1$ and bFGF inhibited expression of MMP3 and bFGF inhibited also the expression of aggrecan and TNF. Conclusions. The response of the studied genes represents a resultant activity of all major cell types building the synovial membrane, i.e. highly specialized synovial fibroblasts, macrophages, epithelial cells and adipocytes. The results of our study can improve understanding of synovial membrane responses to the intraarticular injections of platelet-rich plasma (PRP) used for the treatment of joint ailments, since PRP contains factors which are also present in CIF. (Folia Histochemica et Cytobiologica 2016, Vol. 54, No. 3, 159-165)
\end{abstract}

Key words: cartilage interstitial fluid; synovial membrane; growth factors; ECM proteins; gene expression; qPCR

\section{Introduction}

Articular cartilage has the unique mechanical property of being able to withstand compressive loads.

\footnotetext{
Correspondence address: A. Hyc, Ph.D. Department of Histology and Embryology Medical University of Warsaw

Chalubinskiego 5, 02-004 Warsaw, Poland

tel./fax: +48226295282

e-mail: ahyc@wum.edu.pl
}

This ability is attributed to the association between type II collagen fibrils, decorin and biglycan, which form a network that surrounds and restrains the very large, highly hydrated aggregates of the proteoglycan aggrecan [1]. Chondrocytes produce not only matrix components, but also numerous cytokines and growth factors [2, 3]. Synovial membrane is formed by four main types of cells, i.e. highly specialized synovial fibroblasts, macrophages, epitheliocytes and adipocytes. Functional and metabolic interaction between articular cartilage and synovial membrane is, 
however, poorly characterized. Cells of the synovial membrane may respond to joint loading producing humoral factors such as growth factors, cytokines and enzymes which can be released into the synovial fluid [4]. Indeed, synoviocytes secrete factors inducing synthesis of metalloproteinases by chondrocytes [5] and normal synovial fluid contains proteoglycan-degrading enzymes [4]. Synovial fluid stimulates also collagen type II, glycosaminoglycan and proteoglycan synthesis in articular cartilage [6]. Hyaluronic acid and lubricin produced by synovial membrane participate in articular cartilage lubrication [7]. On the other hand, during joint loading about $10 \%$ of liquid present in cartilage is squeezed and contributes to the hydrostatic lubrication of the articular surfaces $[8,9]$. Since chondrocytes produce numerous growth factors, these factors could be present in the liquid released from loaded cartilage. Thus, synovial fluid probably contains a mixture of factors produced by synovial membrane and articular cartilage cells. Van de Lest et al. [4] found that the synovial fluid collected from ponies after they had been exercised for a week contained increased level of IGF1 in comparison with that obtained after a period of box rest but it was not established whether IGF1 was produced by synovium, articular chondrocytes, or both.

We have previously harvested cartilage interstitial fluid (CIF) from cartilages of young rats and evaluated its influence on gene expression in the synovial membrane [10]. Using ELISA assays we detected in CIF the presence of seven cytokines: basic fibroblast growth factor (bFGF), insulin-like growth factor 1 (IGF1), transforming growth factor $\beta 1$ (TGF $\beta 1$ ), bone morphogenetic protein 7 (BMP7), macrophage colony-stimulating factor (M-CSF), granulocyte colony-stimulating factor (G-CSF) and leukemia inhibitory factor (LIF). CIF stimulated expression of hyaluronan synthases 1 and 2 (HAS1 and HAS2), collagen type I, versican, aggrecan, lubricin, matrix metalloproteinases 2 and 3 (MMP2 and MMP3), tissue inhibitors of metalloproteinases 1, 2 and 3 (TIMP1, TIMP2 and TIMP3), transforming growth factor $\beta 1$ (TGF $\beta 1$ ) and interleukin 6 (IL-6), while the expression of tumor necrosis factor (TNF) and interleukin $1 \beta$ (IL-1 $\beta$ ) was inhibited. Composition of all factors detected in CIF (CIF-like cocktail) stimulated expression of HAS1, lubricin, collagen type I, aggrecan, TIMP1 and TGF $\beta 1$, but contrary to CIF, did not change the expression of MMP-3, IL-6 and TNF [10]. In the present work we analyzed the effects of particular growth factors detected in CIF, either used alone or in combination, to establish which of them exert the strongest effect on the gene expression of ECM proteins in cultured synovial membrane cells.

\section{Material and methods}

Animals. Synovial membranes (SMs) were removed from the knee joints of specific pathogen-free, inbred, male Lewis rats $(\mathrm{n}=42 ; 3$ month-old) purchased from the Animal Unit of the Mossakowski Medical Research Centre at the Polish Academy of Sciences (Warsaw, Poland). The present study and the methods were approved by the Animal Ethics Committee of the Medical University of Warsaw (Warsaw, Poland).

Preparation of rat synovial membranes. Rats were euthanized by inhalation of halothane. After opening the knee joint cavity, the SM was excised together with the patella, the patellar ligament and the joint capsule. The SM with the infrapatellar fat pad was then separated from the other tissues according to the method described previously [11].

Incubation of synovial membrane. As a standard procedure dissected SMs were incubated in flat-bottomed 24-well plates (Corning, Inc., Corning, NY, USA) in humidified atmosphere of $5 \% \mathrm{CO}_{2}$ in air at $37^{\circ} \mathrm{C}$ with constant, slow motion (300 rpm/min), for $4 \mathrm{~h}$. The choice of the incubation time was based on various data from the literature and our own experience [12]. We expected that it will be sufficient for stimulation of most of the studied genes. Furthermore, the 4 hour-long incubation time was dictated by the fear that the response of the synovial membrane kept in vitro for longer times may depend not only on the stimulant used but also be influenced by factors released from synovial membrane cells or adjustment of the tissue to incubation conditions, i.e. to differences in oxygen tension in the joint and incubator. The SM from one knee joint served as the control to the SM from the opposite knee. The control SMs were cultured in RPMI (Gibco-BRL, Paisley, UK) with $0.1 \%$ bovine albumin (Sigma-Aldrich Chemie, Steinheim, Germany) and 1\% Antibiotic/Antimycotic Solution (Sigma-Aldrich). Experimental SMs were incubated in the medium enriched with recombinant cytokines in concentration found in CIF. The following cytokines: bFGF (2.5 ng/mL) G-CSF (25 pg/ $\mathrm{mL}$ ), M-CSF (60 pg/mL), (PromoKine, PromoCell GmbH, Heidelberg, Germany), TGF $\beta 1$ (0.5 ng/mL) (Sigma-Aldrich) and IGF1 (2 ng/mL) (R \& D Systems, Minneapolis, MN, USA) were used in following combinations: TGF $\beta 1 / \mathrm{IGF} 1$, TGF $\beta 1 / \mathrm{IGF} 1 / \mathrm{bFGF}$ or G-CSF/M-CSF. After incubation the total RNA from synovial membrane cells was isolated and the expression of genes encoding HAS1, lubricin, collagen type I, aggrecan, versican, MMP3, TIMP1, IL- $1 \beta$, IL-6, TNF and TGF $\beta 1$ was examined.

Total synovial membrane RNA isolation. RNA was isolated with NucleoSpin ${ }^{\circledR}$ RNA II kit (Macherey-Nagel, Duren, Germany), according to manufacturer's protocol. The quantity and quality of the isolated total RNA was evaluated spectro- 
photometrically using ND-2000 - Spectrophotometer NanoDrop2000 with software for analysis of nucleic acids (Thermo Fisher Scientific, Wilmington, DE, USA).

Reverse transcription. Reverse transcription was performed using the High Capacity cDNA Reverse Transcription Kit (Applied Biosystems, Cheshire, UK), according to the manufacturer's protocol in Eppendorf Mastercycler gradient $\left(10 \min 25^{\circ} \mathrm{C}, 120 \min 37^{\circ} \mathrm{C}, 5 \mathrm{sec} 85^{\circ} \mathrm{C}\right)$. Briefly, $2 \mu \mathrm{L}$ of $10 \times$ RT buffer, $0.8 \mu \mathrm{L}$ of $25 \times$ dNTP Mix, $2 \mu \mathrm{L}$ of $10 \times$ Random Primers, $1 \mu \mathrm{L}$ of Multiscribe Reverse Transcriptase, $4.2 \mu \mathrm{L}$ of nuclease-free water and $10 \mu \mathrm{L}$ of mRNA $(0.5 \mu \mathrm{g})$ per one reaction. cDNA samples were stored at $-20^{\circ} \mathrm{C}$.

Real-time PCR. Real-time PCR was performed in the ABI PRISM 7500 (Applied Biosystems) using 96-well optical plates. Each sample was run in triplicate and was supplied with an endogenous control (Rat GAPDH endogenous control (VIC ${ }^{\circledR} /$ MGB Probe, NM_0170083). For gene expression analysis, the proper inventoried TaqMan expression assays was used (Rn00597231_m1 for HAS1, Rn01490812_m1 for lubricin, Rn01526721_m1 for collagen type I, Rn00573424_m1 for aggrecan, Rn00591740_m1 for MMP3, Rn 00587558_m1 for TIMP1, Rn99999017_m1 for TNF, Rn01410330_m1 for IL-6 and Rn00572010_m1 for $\operatorname{TGF} \beta$ ). All probes were stained with FAM (Applied Biosystems). Reactions was run in $25 \mu \mathrm{L}$ of volume with TaqMan Universal Master Mix, appropriate primer set,
MGB probe and $50 \mathrm{ng}$ of cDNA template. Universal thermal conditions, $10 \mathrm{~min}$ at $95^{\circ} \mathrm{C}, 40$ cycles of $15 \mathrm{sec}$ at $95^{\circ} \mathrm{C}$ and $1 \mathrm{~min}$ at $60^{\circ} \mathrm{C}$, were used. Data analysis was done with sequence detection software ver. 1.2 (Applied Biosystems). The amount of RNA transcript in SMs kept in the control medium was estimated by delta $\mathrm{Ct}$.

Statistical analysis. Data were analyzed by the Wilcoxon matched-pair test (Statistica software) [13]. A p-value $<0.05$ was considered to indicate a statistically significant difference.

\section{Results}

Data presented in Figure 1 document that TGF $\beta 1 /$ /IGF1 stimulated expression of HAS1, lubricin, collagen type I, aggrecan. TGF $\beta 1$ inhibited the expression of MMP3 and TNF and had no effects on TIMP1 and IL-6 expression. TGF $\beta 1 /$ IGF1/bFGF stimulated the expression of HAS1, lubricin and TGF $\beta 1$ and inhibited the expression of TNF. The combination of the latter three growth factors had no effect on the expression of collagen type I, aggrecan, MMP3, TIMP1 and IL-6. G-CSF/M-CSF, which due to their low concentration in CIF were used jointly, stimulated only the expression of aggrecan (Figure 1).

TGF $\beta 1$, bFGF, and IGF1 applied individually exerted inhibitory effect on the expression of lubricin.

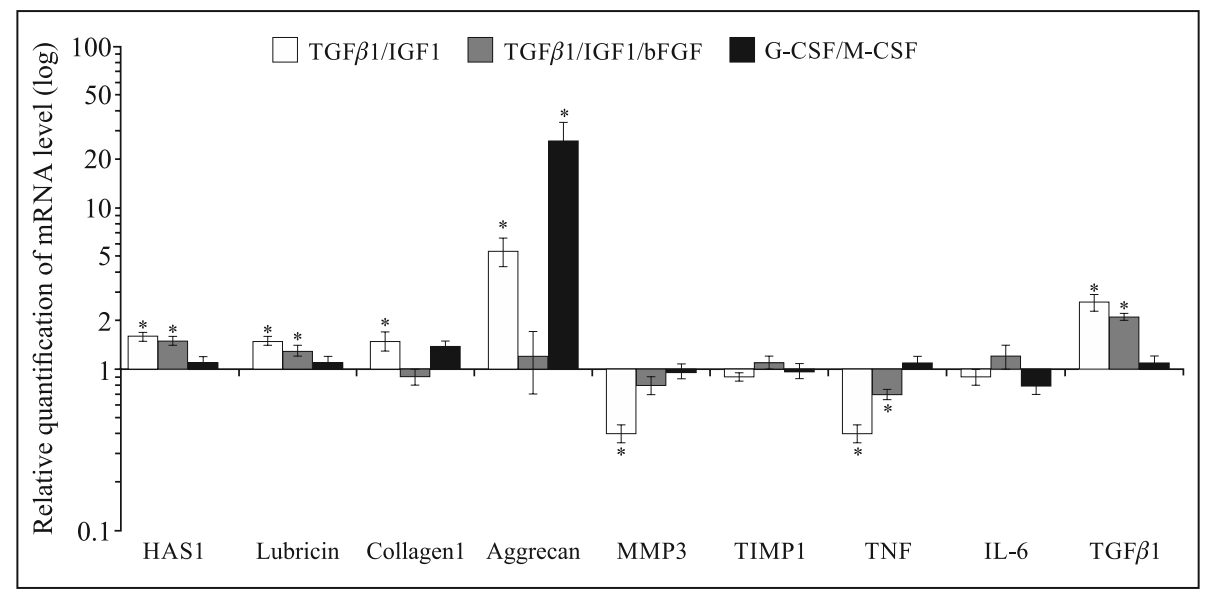

Figure 1. The influence of growth factors on the mRNA level of genes encoding extracellular matrix proteins and cytokines in rat synovial membranes. The mRNA levels for hyaluronan synthase 1 (HAS1), extracellular matrix proteins, matrix metalloproteinase 3 (MMP3), tissue inhibitor of metalloproteinase 1 (TIMP1) and cytokines in the synovial membrane cells were measured by real-time PCR after $4 \mathrm{~h}$ of incubation with TGF $\beta 1 / \mathrm{IGF} 1$, TGF $\beta 1 / \mathrm{IGF} 1 / \mathrm{bFGF}$ or G-CSF/M-CSF. Values are expressed as the means $\pm \mathrm{SE} ; \mathrm{n}=6$ in each group. Relative expression was calculated against the reference gene, GAPDH. Analysis was conducted as a relative quantification study, using control synovial membrane gene expression as a calibrator (value 1). Statistically significant differences in the expression of particular genes in relation to control synovial membranes, according to the Wilcoxon matched-pair test at $\mathrm{p}<0.05$ are marked with asterisks. Abbreviations: TNF — tumor necrosis factor; IL-6 — interleukin-6; TGF $\beta 1$ — transforming growth factor $\beta 1$; IGF1 — insulin-like growth factor 1 ; bFGF — basic fibroblast growth factor. 
Table 1. The influence of growth factors on the mRNA level of genes encoding extracellular matrix proteins and cytokines in rat synovial membranes

\begin{tabular}{|l|c|c|c|}
\hline $\begin{array}{l}\text { Genes } \\
\text { studied }\end{array}$ & $\begin{array}{c}\text { TGF } / 1 \\
(\mathbf{0 . 5} \mathbf{~ n g} / \mathbf{m L})\end{array}$ & $\begin{array}{c}\text { bFGF } \\
\mathbf{2 . 5} \mathbf{~ n g} / \mathbf{m L})\end{array}$ & $\begin{array}{c}\text { IGF1 } \\
(\mathbf{2} \mathbf{~ n g} / \mathbf{m L})\end{array}$ \\
\hline HAS1 & $0.87 \pm 0.06$ & $0.96 \pm 0.05$ & $0.92 \pm 0.04$ \\
\hline Lubricin & $0.57 \pm 0.06^{*}$ & $0.64 \pm 0.09^{*}$ & $0.79 \pm 0.04^{*}$ \\
\hline Collagen1 & $0.81 \pm 0.10$ & $0.94 \pm 0.15$ & $0.76 \pm 0.07$ \\
\hline Aggrecan & $1.83 \pm 0.73$ & $0.43 \pm 0.11^{*}$ & $1.15 \pm 0.16$ \\
\hline MMP3 & $0.75 \pm 0.05^{*}$ & $0.72 \pm 0.04^{*}$ & $1.11 \pm 0.06$ \\
\hline TIMP1 & $0.82 \pm 0.09$ & $0.94 \pm 0.05$ & $1.02 \pm 0.02$ \\
\hline TNF & $0.81 \pm 0.09$ & $0.60 \pm 0.06^{*}$ & $1.25 \pm 0.17$ \\
\hline IL-6 & $1.03 \pm 0.09$ & $0.84 \pm 0.07$ & $1.14 \pm 0.08$ \\
\hline TGF $\beta 1$ & $0.92 \pm 0.04$ & $1.06 \pm 0.05$ & $0.90 \pm 0.05$ \\
\hline
\end{tabular}

The mRNA levels of cytokines and extracellular matrix proteins in rat synovial membrane was measured by real-time PCR after incubation for $4 \mathrm{~h}$ with TGF $\beta 1$, bFGF or IGF1. Relative gene expression was calculated against the expression of the reference gene, GAPDH. Analysis was conducted as a relative quantification study, using control synovial membrane genes' expression as a calibrator (value 1). Values are expressed as the means \pm SE. *Statistically significant difference in the expression of a particular gene in relation to control, Wilcoxon matched-pair test, $\mathrm{p}<0.05$ ( $\mathrm{n}=6$ in each group). Abbreviations: bFGF — basic fibroblast growth factor; HAS1 - hyaluronan synthase 1; IGF1 - insulin-like growth factor 1; IL-6 - interleukin-6; MMP3 - matrix metalloproteinase 3 ; TIMP1 - tissue inhibitor of metalloproteinase 1 ; TGF $\beta 1$ - transforming growth factor $\beta 1$; TNF — tumor necrosis factor.

TGF $\beta 1$ and bFGF inhibited expression of MMP3 and bFGF inhibited also expression of aggrecan and TNF (Table 1).

\section{Discussion}

Stimulation of gene expression under influence of particular growth factors may depend on the reactivity of particular cell types present in the synovial membrane [12]. Thus, the response of the studied genes may represent a summary of activity of several cell types. A precise comparison of gene expression in the rat synovial membrane with data for particular cell types presented by other authors is difficult due to the difference in the origin of the cells, their various modifications in culture, the differences in the period of observation and the dosage of the stimulating agents. With these limitations in mind, we have nevertheless attempted some comparisons to present our data in the more general context.

Hyaluronan synthases (HASs) are expressed by human fibroblast-like synoviocytes [14] and their expression is stimulated by TGF $\beta 1$ [15]. TGF $\beta 1$ stimulated also hyaluronan synthesis in rat synovial membrane [16]. On the other hand, TGF $\beta 1$ decreased the production of hyaluronan in mice epiphyseal growth plate but this production is stimulated by IGF1 [17]. In our present work the expression of HAS1 was not stimulated by TGF $\beta$ or IGF1 acting alone, but both factors applied together exerted distinct stimulatory effect suggestive of certain synergism which, as far as we could establish, has not been observed previously.

Lubricin is produced by fibroblast-like synoviocytes and chondrocytes $[7,18]$. In the previous studies TGF- $\beta 1$ stimulated secretory rate of lubricin by fibroblast-like synoviocytes [19] and accumulation of lubricin in superficial zone chondrocytes and synoviocytes [20]. The discrepancies with the results of our study in which TGF $\beta 1$, bFGF and IGF1 applied individually inhibited expression of lubricin while the effects of composition of TGF $\beta 1 / \mathrm{IGF} 1$ or TGF $\beta 1 /$ /bFGF/IGF1 were opposite may be probably explained by the fact that we have worked with the synovial membrane as a whole organ in which various secretory pathways could be activated.

Collagen type I within synovial membrane is produced by synovial fibroblasts [21]. Both IGF1 [22] and TGF $\beta 1$ [23] enhance collagen type I gene expression in different cell types such as smooth muscle cells [22] or fibroblasts, and Ito cells [23]. In our experiments TGF $\beta 1$, bFGF and IGF1 used individually did not affect its expression but stimulation occurred only when both TGF $\beta 1$ and IGF1 were added to the culture medium. It may be assumed that the exposition of synovial cells to individual factors that lasted 4 hours was too short to activate transcription, but their synergic action was effective. On the other hand, stimulatory effect of TGF $\beta 1 /$ IGF1 was inhibited by the addition of bFGF. Inhibition of IGF1 anabolic action by bFGF was also observed in articular chondrocytes by dimethylmethylene blue (DMMB) assay for proteoglycan production and DNA assay for measurements of cell numbers [24].

Aggrecan within joint tissues is produced by chondrocytes [25] and fibroblast-like synoviocytes [26]. Although IGF1 is thought to be the major stimulator of aggrecan synthesis by articular cartilage cells [27] we did not demonstrate this effect of IGF1 used at the concentration observed in cartilage interstitial fluid [10]. IGF1 and TGF $\beta 1$ used together stimulated aggrecan expression. Similar synergistic action of both agents in increasing the expression of aggrecan mRNA was also observed in rat [28] and human [29] articular chondrocytes. bFGF inhibited expression of aggrecan, similarly as in earlier reports [30]. When bFGF was applied together with TGF $\beta 1$ and IGF1 the expression of aggrecan mRNA was at the level of control value. This observation is in accord with 
that of Loeser et al. [24] who found that the anabolic activity of IGF1 was significantly inhibited by bFGF. In our work, the strongest expression of aggrecan's mRNA occurred after the exposition of synovial cells to G-CSF/M-CSF. This novel observation extends the findings on rat chondrocytes which demonstrated stimulation of aggrecan synthesis by GM-CSF [31] and M-CSF [32]. It has to be noted that GM-CSF and G-CSF being produced by synovial fibroblasts [33] may stimulate aggrecan production in an autocrine or paracrine manner.

MMP3 was shown to be produced in synovial membrane by fibroblast-like synoviocytes [34], adipocytes [35], endothelial cells [36] and macrophages [37]. In the present study the expression of MMP3 mRNA was inhibited by TGF $\beta 1$ and bFGF acting alone and TGF $\beta 1 /$ IGF1 acting jointly while the combination of TGF $\beta 1 /$ IGF1/bFGF had no effect. It is unexpected result, suggesting that IGF1 does not interfere with the action of TGF $\beta 1$ but inhibits action of TGF $\beta$ / /bFGF. Similarly as in this work, TGF $\beta 1$ inhibited also MMP3 expression in synovial membrane after longer exposition lasting 12 hours [12]. Contrary to our result, bFGF induced expression of MMP3 in periodontal ligament (PDL) cells [38].

TIMP1 is expressed in macrophages and monocytes [39], fibroblast-like synoviocytes [40], endothelial cells [36] and adipocytes [41]. TGF $\beta 1$, in concentration $5 \mathrm{ng} / \mathrm{mL}$, stimulated TIMP1 expression in human synovial lining cells isolated from synovial membrane [40]. In our experiments the TIMP1 expression was not changed by any of the studied factors, neither used individually or in combination, probably due to the too low concentration of the cytokines. Moreover, contrary to the other authors, who have studied the isolated populations of synovial lining cells, we worked with the synovium as a whole organ composed of several types of cells.

TNF is produced by various cell types including macrophages [42] and adipose cells [43]. We showed that TNF expression was inhibited by bFGF, and combination of growth factors TGF $\beta 1 /$ IGF1 and TGF $\beta 1 /$ IGF1/bFGF. Although in this study TGF $\beta 1$ used individually at $2 \mathrm{ng} / \mathrm{mL}$ had no effect on the TNF mRNA level the concentration used was probably too low since in our previous work, when synovial membrane was incubated at $10 \mathrm{ng} / \mathrm{mL}$ TGF $\beta 1$ for 12 $h$, the expression of TNF mRNA was enhanced [12].

IL- 6 can be produced by four main cell types of the synovial membrane [21, 42, 44, 45]. In our study none of the factors used, either individually or in combination, changed the expression of the IL-6 gene. Contrary to that, in our previous study, when synovial membrane was incubated for $12 \mathrm{~h}$ at $10 \mathrm{ng} / \mathrm{mL}$ of TGF $\beta 1$, IL- 6 gene expression was enhanced [12].
TGF- $\beta 1$ is expressed by the fibroblast-like synoviocytes, endothelial cells [44], adipocytes [43] and macrophages [46] and can induce its own gene expression in fibroblasts [47], and other cell types [48]. In our study TGF $\beta 1$, bFGF or IGF1 used individually did not significantly change TGF $\beta 1$ expression, but it was raised by TGF $\beta 1 /$ IGF1 and TGF $\beta 1 / \mathrm{IGF} 1 / \mathrm{bFGF}$. In our previous work TGF $\beta 1$ used alone, stimulated its own expression, but the incubation lasted longer and the dose was higher [12].

The response of the studied genes may represent a resultant activity of all major cell types building the synovial membrane, i.e. highly specialized synovial fibroblasts, macrophages, epithelial cells and adipocytes. Synovial membrane within joint cavity may be affected by several agents released by its cells and by articular cartilage.

Studies on the reaction of the synovial membrane as a functional unit to growth factors gain additional perspective since the introduction of intraarticular platelet-rich plasma (PRP) administration as a stimulant for chondrogenesis [49]. Growth factors released from platelets may evoke various, and as yet difficult to predict, reactions of the synovial membrane cells. PRP contains i.a. TGF $\beta 1$, IGF1 and bFGF, the same factors which are present in CIF; thus results of the present work could probably be also useful for the characterization of synovial membrane response to PRP.

\section{Acknowledgements}

The work was supported by the National Science Centre (Poland) on the basis of decision number: DEC-2012/05/B/NZ4/02646.

\section{References}

1. Im HJ, Li X, Muddasani P, Kim GH et al. Basic fibroblast growth factor accelerates matrix degradation via a neuro-endocrine pathway in human adult articular chondrocytes. JCell Physiol. 2008;215:452-463. doi: 10.1002/jcp.21317.

2. Tsuchida AI, Beekhuizen M, Hart MC et al. Cytokine profiles in the joint depend on pathology, but are different between synovial fluid, cartilage tissue and cultured chondrocytes. Arthritis Res Ther. 2014;16:441-456. doi: 10.1186/s13075014-0441-0.

3. Melas IN, Chairakaki AD, Chatzopoulou EI et al. Modeling of signaling pathways in chondrocytes based on phosphoproteomic and cytokine release data. Osteoarthr Cartilage. 2014;22:509-518. doi: 10.1016/j.joca.2014.01.001.

4. van de Lest $\mathrm{CH}$, van den Hoogen BM, van Weeren PR. Loading-induced changes in synovial fluid affect cartilage metabolism. Biorheology. 2000;37:45-55. PMID: 10912177.

5. Bandara G, Georgescu HI, Lin CW, Evans CH. Synovial activation of chondrocytes: evidence for complex cytokine interactions. Agents Actions. 1991;34:285-288.

6. Lee DA, Sahil V, Stockton EF, Stanton JS, Bentley G. Effect of normal synovial fluid on the metabolism of articular 
chondrocytes in vitro. Clin Orthop Rel Res. 1997;342:228-238. PMID: 9308545.

7. Hui AY, McCarty WJ, Masuda K, Firestein GS, Sah RL. A systems biology approach to synovial joint lubrication in health, injury, and disease. Wiley Interdiscip Rev Syst Biol Med. 2012;4:15-37. doi: 10.1002/wsbm.157.

8. McCutchen CW. Sponge-hydrostatic and weeping bearings. Nature. 1959;184:1284-1285.

9. Caligaris M, Ateshian GA. Effects of sustained interstitial fluid pressurization under migrating contact area, and boundary lubrication by synovial fluid on cartilage friction. Osteoarthr Cartilage. 2008;16:1220-1227. doi: 10.1016/j.joca.2008.02.020.

10. Hyc A, Moskalewski S, Osiecka-Iwan A. Influence of cartilage interstitial fluid on the mRNA level of matrix proteins, cytokines, metalloproteases and their inhibitors in synovial membrane. Int J Mol Med. 2016;38:937-942. doi: 10.3892/ijmm.2016.2684.

11. Hyc A, Osiecka-Iwan A, Dziunycz P, Moskalewski S. Preparation of rat synovial membrane for studies of cytokine secretion. Folia Biol Cytochem. 2007;45:57-60. PMID: 17378248

12. Hyc A, Osiecka-Iwan A, Niderla-Bielińska J, Moskalewski S. Influence of LPS, TNF, TGF- $\beta 1$ and IL- 4 on the expression of MMPs, TIMPs and selected cytokines in rat synovial membranes incubated in vitro. Int J Mol Med. 2011;27:127-137. doi: 10.3892/ijmm.2010.550.

13. Livak KJ, Schmittgen TD. Analysis of relative gene expression data using real-time quantitative PCR and the 2(-Delta Delta C(T)) Method. Methods. 2001;25:402-408. doi: 10.1006/ meth.2001.1262.

14. Stuhlmeier KM, Pollaschek CP. Differential effect of transforming growth factor $\beta$ (TGF- $\beta 1$ ) on the genes encoding hyaluronan synthases and utilization of the p38 MAPK pathway in TGF- $\beta 1$-induced hyaluronan synthase 1 activation. J Biol Chem. 2004;5:8753-8760. doi: 10.1074/jbc.M303945200.

15. Campo GM, Avenoso A, Campo S, D'Ascola A, Traina P, Calatroni A. Effects of cytokines on hyaluronan synthase activity and response to oxidative stress by fibroblasts. $\mathrm{Br} \mathrm{J}$ Biomed Sci. 2009;66:28-36. PMID: 19348124.

16. Hyc A, Osiecka-Iwan A, Niderla-Bielińska J, Jankowska-Steifer E, Moskalewski S. Pro- and anti-inflammatory cytokines increase hyaluronan production by rat synovial membrane in vitro. Int J Mol Med. 2009;24:579-585. doi: 10.3892/ijmm_00000268.

17. Pavasant $P$, Shizari T, Underhill CB. Hyaluronan synthesis by epiphyseal chondrocytes is regulated by growth hormone, insulin-like growth factor and transforming growth factor-1: Matrix Biol. 1996;15:423-432. PMID: 9049980.

18. Kosinska MK, Ludwig TE, Liebisch $\mathrm{G}$ et al. Articular joint lubricants during osteoarthritis and rheumatoid arthritis display altered levels and molecular species. PLOS One. 2015;10:e0125192. doi: 10.1371/journal.pone.0125192.

19. Blewis ME, Lao BJ, Schumacher BL et al. Interactive cytokine regulation of synoviocyte lubricant secretion. Tissue Eng Part A. 2010;16:1329-1337. doi: 10.1089/ten.TEA.2009.0210.

20. Niikura T, Reddi AH. Differential regulation of lubricin/superficial zone protein by transforming growth factor $\beta /$ Bone morphogenetic protein superfamily members in articular chondrocytes and synoviocytes. Arthr Rheum. 2007;56:2312-2321. doi: 10.1002/art.22659.

21. Warnock JL, Spina J, Bobe G et al. Culture of canine synoviocytes on porcine intestinal submucosa scaffolds as a strategy for meniscal tissue engineering for treatment of meniscal injury in dogs. Vet J. 2014;199:49-56. doi: 10.1016/j. tvj1.2013.10.038

22. Blackstock $C D$, Higashi $Y$, Sukhanov S et al. Insulin-like growth factor-1 increases synthesis of collagen type I via induction of the mRNA-binding protein LARP6 expression and binding to the 5' stem-loop of COL1a1 and COL1a2 mRNA. J Biol Chem. 2014;289:7264-7274. doi: 10.1074/jbc.M113.518951.

23. Verrecchia F, Mauviel A. TGF- $\beta$ and TNF-a: antagonistic cytokines controlling type I collagen gene expression. Cell Signal. 2004;16:873-880. doi: 10.1016/j.cellsig.2004.02.007.

24. Loeser RF, Chubinskaya S, Pacione C, Im HJ. Basic fibroblast growth factor inhibits the anabolic activity of insulin-like growth factor 1 and osteogenic protein 1 in adult human articular chondrocytes. Arthritis Rheum. 2005;52:3910-3917. doi: 10.1002/art.21472.

25. Hanyecz A, Olasz K, Tarjanyi O et al. Proteoglycan aggrecan conducting T cell activation and apoptosis in a murine model of rheumatoid arthritis. Biomed Res Int. 2014;942148. doi: $10.1155 / 2014 / 942148$.

26. Spina J, Warnock J, Duesterdieck-Zellmer K, Baltzer W, Ott J, Bay B. Comparison of growth factor treatments on the fibrochondrogenic potential of canine fibroblast-like synoviocytes for meniscal tissue engineering. Vet Surg. 2014;43:750-760. doi: 10.1111/j.1532-950X.2014.12170.x.

27. Gaissmaier C, Koh JL, Weise K. Growth and differentiation factors for cartilage healing and repair. Injury. 2008;39(Suppl1): 88-96. doi: 10.1016/j.injury.2008.01.035.

28. Tsukazaki T, Usa T, Matsumoto T et al. Effect of transforming growth factor-beta on the insulin-like growth factor-I autocrine/paracrine axis in cultured rat articular chondrocytes. Exp Cell Res. 1994;215:9-16. doi: 10.1006/excr.1994.1307.

29. Yaeger PC, Masi TL, Buck de Ortiz JL, Binette F, Tubo R, McPherson JM. Synergistic action of transforming growth factor- $\beta$ and insulin-like growth factor-I induces expression of type II collagen and aggrecan genes in adult human articular chondrocytes. Exp Cell Res. 1997;237:318-325. doi: 10.1006/ excr.1997.3781.

30. Ellman MB, Yan D, Ahmadinia K, Chen D, An HS, Im HJ. Fibroblast growth factor control of cartilage homeostasis. J Cell Biochem. 2013;114:735-742. doi: 10.1002/jcb.24418.

31. Quintero M, Colantuoni G, Khatib AM, Panasyuk A, Lomri A, Mitrovic DR. Granulocyte-macrophage colony stimulating factor activates proteoglycan, type II collagen, and cAMP production by rat articular chondrocytes through specific binding sites. J Rheumatol. 2001;28:2075-2084. PMID: 11550977.

32. Nakao K, Kubota S, Doi $\mathrm{H}$ et al. Collaborative action of $\mathrm{M}-\mathrm{CSF}$ and CTGF/CCN2 in articular chondrocytes: possible regenerative roles in articular cartilage metabolism. Bone. 2005;36:884-892. doi: 10.1016/j.bone.2004.10.015.

33. Li Y, Li P, Lin SH, Zheng YQ, Zheng XX. Paeonol inhibited TNF-alpha-induced GM-CSF expression in fibroblast-like synoviocytes. Int J Clin Pharmacol Ther. 2014;52:986-996. doi: $10.5414 / \mathrm{CP} 202127$.

34. Santangelo KS, Johnson AL, Ruppert AS, Bertone AL. Effects of hyaluronan treatment on lipopolysaccharidechallenged fibroblast-like synovial cells. Arthritis Res Ther. 2007;9:R1. doi: 10.1186/ar2104.

35. O'Hara A, Lim FL, Mazzatti DJ, Trayhurn P. Microarray analysis identifies matrix metalloproteinases (MMPs) as the genes whose expression is upregulated in human adipocytes by macrophage-conditioned medium. Pflugers Arch. 2009;458:1103-1114. doi: 10.1007/s00424-009-0693-8.

36. Nelimarkka LO, Nikkari ST, Ravanti LS, Kähäri VM, Järveläinen HT. Collagenase-1, stromelysin-1 and $92 \mathrm{kDa}$ gelatinase are associated with tumor necrosis factor-alpha induced morphological change of human endothelial cells in vitro. Matrix Biol. 1998;17:293-304. PMID: 9749945.

37. Ma JD, Zhou JJ, Zheng DH et al. Serum matrix metalloproteinase-3 as a noninvasive biomarker of histological synovitis 
for diagnosis of rheumatoid arthritis. Mediators Inflamm. 2014;179284. doi: 10.1155/2014/179284.

38. Hakki SS, Hakki EE, Nohutcu RM. Regulation of matrix metalloproteinases and tissue inhibitors of matrix metalloproteinases by basic fibroblast growth factor and dexamethasone in periodontal ligament cells.J Periodontal Res. 2009;44:794-802. doi: 10.1111/j.1600-0765.2008.01192.x.

39. Shapiro SD, Fliszar CJ, Broekelmann TJ, Mecham RP, Senior RM, Welgus HG. Activation of the 92-kDa gelatinase by stromelysin and 4-aminophenylmercuric acetate. $J$ Biol Chem. 1995;270:6351-6356. PMID: 7890773.

40. Gatsios P, Haubeck HD, Van de Leur E et al. Oncostatin M differentially regulates tissue inhibitors of metalloproteinases TIMP-1 and TIMP-3 gene expression in human synovial lining cells. Eur J Biochem. 1996;241:56-63. PMID: 8898888.

41. Meissburger B, Stachorski L, Röder E, Rudofsky G, Wolfrum C. Tissue inhibitor of matrix metalloproteinase 1 (TIMP1) controls adipogenesis in obesity in mice and in humans. Diabetologia. 2011;54:1468-1479. doi: 10.1007/s00125-011-2093-9.

42. Scotté M, Hiron M, Masson S et al. Differential expression of cytokine genes in monocytes, peritoneal macrophages and liver following endotoxin- or turpentine-induced inflammation in rat. Cytokine. 1996;8:115-120. doi: 10.1006/cyto.1996.0016.

43. Liu LF, Shen WJ, Ueno M, Patel S, Kraemer FB. Characterization of age-related gene expression profiling in bone marrow and epididymal adipocytes: BMC Genomics. 2011;12:212-238. doi: 10.1186/1471-2164-12-212.
44. Schwachula A, Riemann D, Kehlen A, Langner J. Characterization of the immunophenotype and functional properties of fibroblast-like synoviocytes in comparison to skin fibroblasts and umbilical vein endothelial cells. Immunobiology. 1994;190:67-92. doi: 10.1016/S0171-2985(11)80284-6.

45. Distel E, Cadoudal T, Durant S, Poignard A, Chevalier X, Benelli C. The intrapatellar fat pad in knee osteoarthritis. An important source of interleukin-6 and its soluble receptor. Arthritis Rheum. 2009;60:3374-3377. doi: 10.1002/ art.24881.

46. Spencer M, Yao-Borengasser A, Unal R et al. Adipose tissue macrophages in insulin-resistant subjects are associated with collagen VI and fibrosis and demonstrate alternative activation. Am J Physiol Endocrinol Metab. 2010;299:1016-1027. doi: 10.1152/ajpendo.00329.2010.

47. Piek E, Ju WJ, Heyer J et al. Functional characterization of transforming growth factor b signaling in Smad2- and Smad-3-deficient fibroblasts. J Biol Chem. 2001;276:19945-19953. doi: $10.1074 /$ jbc.M102382200.

48. van Obberghen-SchillingE, Roche NS, Flanders KC, Sporn MB, Roberts $\mathrm{AB}$. Transforming growth factor $\beta 1$ positively regulates its own expression in normal and transformed cells. J Biol Chem. 1988;263:7741-7746. PMID: 3259578.

49. Kabiri A, EsfandiariE, Esmaeili A, Hashemibeni B, Pourazar A, Mardani M. Platelet-rich plasma application in chondrogenesis. Adv Biomed Res. 2014;3:138-150. doi: 10.4103/22779175.135156. 